\title{
Minireview
}

\section{The Neuroendocrine Basis of Anorexia Nervosa and Its Impact on Bone Metabolism}

\author{
Madhusmita Misra ${ }^{a, b} \quad$ Anne Klibanski ${ }^{a}$ \\ ${ }^{a}$ Neuroendocrine Unit and bediatric Endocrine Unit, Massachusetts General Hospital and Harvard Medical School, \\ Boston, Mass., USA
}

\section{Key Words}

Anorexia nervosa $\cdot$ Growth hormone $\cdot$ Cortisol $\cdot$

Gonadal steroids - Ghrelin - Leptin - Peptide YY •

Adiponectin - Bone density - Bone turnover markers •

Bone microarchitecture

\section{Abstract \\ Anorexia nervosa (AN) is a condition of profound undernutri- tion associated with alterations in various neuroendocrine axes, many of which contribute to a marked impairment in bone accrual and low bone mineral density. This review focuses on changes in the hypothalamo-pituitary-gonadal axis, the growth hormone insulin-like growth factor-1 axis, and the hypothalamo-pituitary-adrenal axis in AN, as well as alterations in various appetite-regulating hormones. In ad- dition, the review discusses low bone mineral density and altered bone microarchitecture in AN, the pathophysiology underlying impaired bone metabolism, and possible thera- peutic strategies to optimize bone health.}

Copyright $\odot 2011$ S. Karger AG, Basel

\section{KARGER}

Fax +4161306 1234

E-Mail karger@karger.ch

www.karger.com
(C) 2011 S. Karger AG, Basel

Accessible online at: www.karger.com/nen

\section{Introduction}

Anorexia nervosa (AN), a condition of profound undernutrition, is characterized by alterations in multiple neuroendocrine axes, and while these changes are primarily physiological and adaptive, many of these hormonal alterations also contribute to low bone density, a serious pathological consequence of this eating disorder. Based on DSM-IV criteria [1], the diagnostic features for AN include weight loss, a failure to gain weight or maintain weight, an altered body image, a deep fear of gaining weight, and in women, amenorrhea for at least 3 months. The condition is prevalent amongst young women, and $0.2-4 \%$ of adolescent girls and college-aged women are reported to suffer from this devastating eating disorder [2]. This disorder can also occur in older women, and, undernutrition and its associated hormone abnormalities can exacerbate bone loss in the peri- and postmenopausal age group. Although less common, males can also develop AN, which often goes undiagnosed longer than in females with the disorder, and the impact on neuroendocrine axes and bone is much less well studied. In this review we will discuss the various neuroendocrine alterations in $\mathrm{AN}$ and the subsequent impact on bone. 


\section{Growth Hormone Insulin-Like Growth Factor-1 Axis}

AN is associated with a nutritionally acquired resistance to growth hormone (GH) with decreased liver production of insulin-like growth factor-1 (IGF-1) and elevated $\mathrm{GH}$ levels [3-5]. Low levels of the GH-binding protein [6] indicate decreased expression of the $\mathrm{GH}$ receptor, which likely accounts for the state of GH resistance in the starved state. This resistance may also be mediated by fibroblast growth factor-21 (FGF21) [7]. FGF21 is a member of the FGF family, and is known to stimulate glucose uptake in adipocytes, and also increases energy expenditure and fat utilization $[8,9]$. In addition, FGF21 transgenic mice have high GH but low IGF-1 levels, and FGF21 overexpression induces GH resistance by inhibiting STAT-5, a key transcription factor in the $\mathrm{GH}$-signaling cascade [10]. We have demonstrated a positive association of elevated FGF21 levels with GH concentrations in adolescent girls with $\mathrm{AN}$, and an inverse association with IGF-1, consistent with this animal model of GH resistance [7].

IGF-1 levels vary with the degree of undernutrition, and correlate positively with body mass index (BMI) and fat mass [3]. GH levels are higher in girls and women with AN than in controls [3-5], and these higher levels are consequent to (i) reduced feedback at the level of the pituitary and hypothalamus from low IGF-1 levels, and to (ii) higher levels of ghrelin, a GH secretagogue, compared to controls [11]. Basal, pulsatile and total GH secretion are increased in $\mathrm{AN} \mathrm{[3-5];} \mathrm{the} \mathrm{increase} \mathrm{in} \mathrm{pulsatile} \mathrm{secretion}$ is subsequent to increased pulse mass and duration with increased pulse frequency in adult women [5], whereas increased pulse frequency alone has been reported in adolescents with AN [3]. GH suppression following an oral glucose load is impaired in girls with AN as compared to controls [12], although whether this altered suppressibility is due entirely to $\mathrm{GH}$ dysregulation or in part related to high levels of endogenous GH secretion is unclear. There is also greater disorderliness of GH secretion in $\mathrm{AN}$, as indicated by greater approximate entropy $[3,5]$. An interesting question is whether this state of GH resistance in $\mathrm{AN}$ can be overcome with supraphysiological doses of GH. In a recent study, we randomized 19 women with AN to supraphysiological doses of recombinant human (rh) GH or placebo for a 3-month period, and found no significant increase in IGF-1 levels using GH doses up to 5-6 times adult physiological replacement [13]. These data are consistent with a block in IGF-1 secretion at the liver induced by starvation. In contrast, IGF-1 levels are known to increase with weight recovery to approximate levels in healthy adolescents of comparable age and ma- turity [14]. One study examined the impact of administration of the GH secretagogue, ghrelin, on GH and IGF1 secretion in 5 young women with $\mathrm{AN}$, and reported an increase in IGF-1 and decrease in GH levels in 1 woman [15]. However, the other women did not demonstrate these changes, suggestive of a resistance to ghrelin effects in $\mathrm{AN}$.

\section{Hypothalamo-Pituitary-Gonadal Axis}

Hypothalamic amenorrhea is a characteristic feature of AN, and has been attributed to a state of severe energy deficit from restricted energy intake, increased energy expenditure or both. Women and adolescent girls with AN have lower levels of estradiol and testosterone than controls of comparable age $[3,14]$. In one study in adolescent girls, $28 \%$ of girls with AN were premenarchal, compared with $11 \%$ of healthy adolescent girls in the same age range [16]. Similarly, lower levels of sex steroids have been reported in adolescent boys with AN compared with controls [17]. Additionally, gonadotropin secretion patterns have been studied in adult women with $\mathrm{AN}$ and indicate a reversal to an early pubertal state of nighttime entrainment of luteinizing hormone (LH) pulsatility or a prepubertal state of very low amplitude LH pulses, indicative of impaired gonadotropin-releasing hormone $(\mathrm{GnRH})$ pulsatility [18]. Potential neuroendocrine links between the energy deficit state of AN and impaired $\mathrm{GnRH}$ pulsatility include reduced fat mass and alterations in hormones that are secreted or regulated by fat, such as leptin, ghrelin, peptide YY (PYY), adiponectin, cortisol, insulin and IGF-1. In one prospective study, all adolescent girls with AN who attained a fat mass of $24 \%$ or greater over the follow-up period resumed menstrual function, whereas those with a fat mass of $18 \%$ or less continued to be amenorrheic, with significant overlap of menstrual status in girls whose fat mass ranged between $18-24 \%$ [19].

\section{Ghrelin}

Ghrelin is an orexigenic peptide that is secreted by the oxyntic cells of the stomach, and ghrelin levels reflect energy status. Levels typically peak before meals and nadir about 30 minutes following meals [20, 21]. This hormone is also a GH and adrenocorticotropic hormone (ACTH) secretagogue $[22,23]$, and ghrelin administration inhibits gonadotropin pulsatility in animal and human models $[24,25]$. Ghrelin levels are high in AN [26], presumably an adaptive response to the low energy state, and levels 
correlate inversely with BMI and fat mass $[11,27]$. Although patients with AN have been show to have a hyperresponsiveness to $\mathrm{GH}$-releasing hormone $(\mathrm{GHRH})$ administration compared to normal weight controls, their $\mathrm{GH}$ response to ghrelin administration is blunted. This is consistent with desensitization of the $\mathrm{GH}$ secretagogue (GHS) receptor [28].

Increased levels of ghrelin are consequent to greater ghrelin pulse amplitude, and are positively associated with GH and cortisol in AN. Additionally, similar to GH, girls with AN demonstrate higher ghrelin levels following an oral glucose load than controls, although the absolute decrease in ghrelin following glucose administration does not differ between the groups [12]. The dependence of ghrelin elevations on body weight has been shown by Otto et al. [29] who demonstrated that women with AN and ghrelin elevations had normalization of ghrelin levels with weight restoration.

We have demonstrated inverse associations of ghrelin with $\mathrm{LH}$ and estradiol in girls with $\mathrm{AN}$, consistent with animal data [11].

\section{Peptide YY}

PYY is an anorexigenic hormone that is secreted by the endocrine L cells of the distal gut, which produces its effects by binding to the $\mathrm{Y} 2$ receptor of neuropeptide $\mathrm{Y}$ (which is orexigenic) and decreasing neuropeptide $\mathrm{Y}$ secretion [30]. Levels of PYY are high in girls with AN compared with healthy adolescents of comparable maturity [31], although the expected adaptive response would be a decrease in secretion of this anorexigenic peptide given the state of low energy intake. Levels of PYY in AN correlate inversely with fat intake and with BMI [31]; however, a direct role of high PYY in mediating decreased food intake in AN appears unlikely. Interestingly, animal studies indicate that PYY impacts the hypothalamo-pituitary-gonadal axis at the level of the hypothalamus and the pituitary [32], and in our studies, PYY was inversely associated with gonadotropin levels [31].

\section{Adiponectin}

Adiponectin is an adipokine that is low in conditions of obesity, and low adiponectin levels predict higher insulin resistance [33]. Although one would expect high levels of adiponectin in $\mathrm{AN}$, a condition of low insulin resistance, levels of adiponectin have been variably reported to be high, normal or low in AN compared with healthy controls [34-36]. Normal and low adiponectin levels have been attributed to low fat mass in $\mathrm{AN}$, given that adiponectin is secreted by adipocytes, and in fact, after adjusting for fat mass, we did find higher adiponectin levels in adolescent girls with AN compared with healthy adolescents [35]. Additionally, adiponectin has been demonstrated to inhibit gonadotropin secretion from gonadotropes through an AMP-activated protein kinase-mediated mechanism [37], and may be yet another contributor to the state of hypogonadotropic hypogonadism in AN.

\section{Leptin}

Leptin is an adipocytokine and a marker of energy status and fat mass [38]. Leptin is also important for normal reproductive function, and leptin-deficient mice and humans are hypogonadal [39]. The link between leptin and reproductive function has been demonstrated conclusively by studies that show that the hypogonadal state in women with hypothalamic amenorrhea is reversed following leptin replacement [40]. Leptin levels are markedly reduced in AN commensurate with reductions in fat mass, and decreases in leptin secretion are primarily a consequence of reduced leptin pulse amplitude $[41,42]$. Weight recovery in AN is associated with a trend towards increases in leptin levels, and adolescent girls with $\mathrm{AN}$ who recover menses have greater increases in leptin from baseline than those who do not recover menses [19]. In adults with AN and comparable BMIs, preservation of gonadal function was seen in women with higher body fat. Patients with eumenorrhea had more body fat and higher serum leptin levels than their amenorrheic counterparts of similar weight. Decreased bone density at the spine was less severe in this group suggesting that higher fat mass and leptin levels may be important for preservation of normal menstrual function in such patients [43].

Although it is tempting to speculate that increases in leptin above a specific threshold are necessary for resumption of menses, data available thus far argue against this [19]. Additionally, our studies have shown that changes in fat mass are a stronger predictor of menstrual recovery in adolescent girls with AN than are changes in leptin levels [19]. These data suggest that changes in fat mass are likely associated with changes in other neuroendocrine factors as well, and that changes in these factors, in addition to changes in leptin, may be important for normalization of GnRH pulsatility and for menstrual recovery. Low leptin levels in AN also have an impact on other hormones, and regression models have shown that low leptin levels in AN predict increased GH and cortisol secretion [42]. 


\section{Other Hormones}

IGF-1 and insulin impact the hypothalamo-pituitary-gonadal axis at multiple levels; levels of IGF-1 and insulin are significantly lower in girls with AN than in controls [35] and may contribute to the hypogonadal state.

\section{Hypothalamo-Pituitary-Adrenal Axis}

Marked alterations occur in the hypothalamo-pituitary-adrenal axis in AN. Serum and urinary cortisol levels are significantly higher than in controls $[44,45]$, and correlate inversely with BMI and fat mass. An important determinant of cortisol concentrations in $\mathrm{AN}$ is the fasting glucose level [45], and it is possible that cortisol, an important gluconeogenic hormone, increases in $\mathrm{AN}$ as a counterregulatory response to reduced food intake in order to maintain a state of euglycemia. In fact, in experimental animal models, glucose administration has been demonstrated to normalize the cortisol response to stress. Increased cortisol secretion in adolescents with $\mathrm{AN}$ is a consequence of an increased number of secretory bursts as well as a longer half-life [45]. High cortisol levels in AN are associated with low leptin and high ghrelin levels. Interestingly, cortisol levels are higher in girls with AN who are more likely to gain weight in subsequent months, and baseline cortisol levels in AN positively predict subsequent increases in fat mass and resumption of menses [19]. Similarly, in adults with AN, higher baseline cortisol levels predict greater subsequent increases in trunk fat [46]. Studies suggest that hypercortisolemia may have a deleterious impact on gonadotropin secretion [47], and high cortisol levels in AN may thus also contribute to the associated state of hypogonadotropic hypogonadism. Adrenal androgens have been reported to be lower in women with AN in some [48], but not all [49], studies.

\section{Hypothalamo-Pituitary-Thyroid Axis}

Thyroid function tests in AN resemble those seen in the sick euthyroid state, and total triiodothyronine $\left(\mathrm{T}_{3}\right)$ levels, particularly, are associated closely with markers of nutritional status such as BMI and fat mass. In one study of adolescent girls with AN compared with controls, we observed no differences between the groups for TSH levels, while total $\mathrm{T}_{3}$ and total thyroxine $\left(\mathrm{T}_{4}\right)$ levels were significantly lower in $\mathrm{AN}$, and free $\mathrm{T}_{4}$ trended low- er [42]. Leptin administration has been shown to increase levels of thyroid hormones in women with hypothalamic amenorrhea [40], and in AN, positive associations have been reported of leptin with total $\mathrm{T}_{4}$ and $\mathrm{T}_{3}$ levels in adults [50] and in adolescents [42]. Additionally, ghrelin has an inhibitory effect of secretion of thyroidstimulating hormone [51], and studies indicate inverse associations of ghrelin with levels of thyroid hormones in AN [11]. These data suggest that low leptin and high ghrelin levels may contribute to lower thyroid hormone levels in $\mathrm{AN}$.

\section{Other Hormones}

Prolactin levels are usually not altered in AN except as a consequence of associated medications including antipsychotics and some selective serotonin reuptake inhibitors (SSRIs).

\section{Bone Metabolism}

\section{Bone Density and Markers of Bone Turnover}

$\mathrm{AN}$ is a high-risk factor for low bone density, and reduced rates of bone mass accrual occur in adolescents, as well as loss of established bone mass in adults $[16,49,52$, 53]. More than $90 \%$ of adult women with AN are osteopenic, and almost $40 \%$ are osteoporotic at one or more sites as defined by a T-score of -2.5 or lower [54]. Of note, the T-score compares any individual's bone density to the mean bone density for young adults, whereas the Z-score compares the individual's bone density to the mean for age and gender. In adolescent girls, $Z$-scores of $<-1$ are seen in more than $50 \%$ and $Z$-scores of $<-2$ in about $10 \%$ compared with 25 and $2 \%$, respectively, of controls [16]. In adult women, we have demonstrated that low bone density is associated with increased marrow fat, which is of interest given the emerging interest in the bone-fat connection [55]. While all sites (spine, hip, femoral neck and whole body) are affected in AN, the greatest deficits in bone mass and bone density are typically seen at the lumbar spine, which is primarily trabecular bone $[16,54$, 56]. In children, a concern is that dual energy X-ray absorptiometry (DXA) measures of bone density can be affected by body size or pubertal delay, and this is of particular relevance in adolescents with AN where stunting of growth from poor nutrition and delayed or arrested puberty may lead to an erroneous and over-reporting of low bone density. However, height-adjusted measures of 
bone density (such a lumbar bone mineral apparent density and whole body bone mineral content adjusted for height) are also lower in girls with AN than in controls, and correcting for height in multivariate models continues to demonstrate significant deficits in bone mass and bone density in AN [57]. Although much less common, AN can affect males as well and we have reported marked reductions in bone density in adolescent boys with AN compared with controls, although in boys, areas of primarily cortical bone, such as the hip and femoral neck, appear to be affected more than sites of primarily trabecular bone [17].

Adults with AN demonstrate an uncoupling of bone turnover, with a decrease in markers of bone formation, but an increase in markers of bone resorption [58]. This has been attributed to a loss of endogenous factors leading to abnormal bone formation and estrogen deficiency leading to an increase in bone resorption. Conversely, in adolescents with AN, there is a decrease in levels of markers of bone formation and resorption [3,59], indicating a low bone turnover state, which is in contrast to normal adolescence, a time of increased bone turnover from increased bone modeling.

The adolescent years are a time of marked increases in bone mass accrual towards the attainment of peak bone mass, an important determinant of bone health and fracture risk in later life, and the development of $\mathrm{AN}$ in the pubertal years raises significant concerns for not only an immediate increase in fracture risk, but also for future bone health. Our studies indicate a slight decrease in bone mass and DXA measures of bone density in girls with AN who persist at a low-weight state, compared with healthy adolescents, who have a continued increase in bone mass and DXA measures of bone density over a follow-up period [57]. As a consequence, Z-scores (which compare bone density to the mean for age and gender) continue to decrease in girls with AN over time. Of importance, adult women who develop AN in the adolescent years have lower measures of bone density than those who develop AN in adult life, even when the duration of amenorrhea is comparable, emphasizing the critical role for the pubertal years in attainment of peak bone mass [60].

\section{Bone Structure}

In recent years, strong data have emerged to indicate that bone microarchitecture as assessed by computed tomography (CT) may be a better indicator of bone strength and fracture risk than DXA measures of bone density [reviewed in 61, 62]. Use of high-resolution peripheral quantitative $\mathrm{CT}$ allows characterization of cortical and trabecular volumetric bone density, and also provides information regarding trabecular number, thickness and separation. In addition, finite element analysis from high-resolution peripheral quantitative CT provides measures of bone strength. Flat panel high-resolution volume $\mathrm{CT}$ is another imaging modality that allows assessment of trabecular structural parameters and bone trabecular volume. We have demonstrated using flat panel high-resolution volume CT that adolescent girls with AN have lower bone trabecular volume and trabecular thickness, and greater trabecular separation than healthy adolescent girls even in milder forms of AN when bone density measures do not differ between the groups [63]. Our studies [64] and those of Milos et al. [65] also indicate lower bone trabecular volume and trabecular number and greater trabecular separation in adult women with AN compared with controls. Milos et al. [65] have also reported lower cortical thickness in women with AN. More recently, we have demonstrated using finite element analysis that bone strength parameters are significantly reduced in women with AN compared with controls [66].

\section{Mechanisms Underlying Low Bone Density in AN}

Many factors contribute to low bone density in AN. Important contributing factors include low BMI and lean body mass [16]. The pull of muscle on bone has anabolic effects through activation of osteocytes (the 'mechanostat'), and low BMI in AN is associated with reductions in both fat mass and lean mass, with consequent effects on bone. Lean mass is an important determinant of bone density at almost all sites in both genders, but particularly affects bone density at the hip and whole body. Another important determinant of low bone density in AN is the hypogonadal state. The duration of amenorrhea predicts the extent of bone loss in girls and women with AN [49], and testosterone levels are a strong predictor of bone density in boys with AN [17]. In addition, changes in testosterone over time predict changes in bone turnover markers over the same duration in girls with AN [14], and low testosterone levels predict lower bone density and structure in women with AN [64]. Some studies have implicated low levels of adrenal androgen precursors in the low bone density state seen in AN [48]. We found that both total and free testosterone, but not dehydroepiandrosterone sulfate, were markedly reduced in women with AN than in controls; the lowest levels were found in woman using oral contraceptives. There was a positive correlation between both total and free testoster- 
one levels as well dehydroepiandrosterone sulfate levels and bone density [67].

Normal increases in GH and IGF-1 during puberty are critical for increases in bone formation in the pubertal years, and the acquired GH-resistant state in $\mathrm{AN}$ is another factor that contributes to low bone density in AN. Whereas GH levels correlate strongly with bone turnover markers in healthy adolescent girls, this association is completely lost in girls with AN, suggesting resistance to $\mathrm{GH}$ at the level of bone in addition to hepatic resistance to $\mathrm{GH}[3]$.

Our recent studies indicate that administration of rhGH in supraphysiological doses (5-6 times adult replacement) is unable to cause an increase in markers of bone formation in women with $\mathrm{AN}$, confirming the state of GH resistance [13]. Additionally, low IGF-1 levels are closely associated with low levels of bone formation markers and low bone density, and increases in IGF-1 levels with weight gain in AN predict increases in bone formation markers and in bone density $[49,59]$. Studies in adult women with AN have shown that women treated for 9 months with rhIGF-1 had greater improvements in spine bone mass than a placebo group and that this effect was greatest in women receiving oral contraceptives in addition to rhIGF-1 [68].

The higher cortisol levels in girls and women with AN compared with controls also predict lower bone density measures and lower levels of bone formation markers [45], consistent with the known deleterious effects of cortisol on bone. Other hormonal alterations that contribute to low bone density and lower levels of bone formation markers include low levels of leptin and insulin, and high levels of PYY [31, 35]. In women with $\mathrm{AN}$, mean overnight PYY levels correlated negatively with bone density at multiple skeletal sites, and at the spine PYY was a major determinant of bone density variability [69].

Despite reduced caloric intake in $\mathrm{AN}$, intake of calcium and vitamin D (primarily through supplements) is better in AN than in healthy women and girls, and calcium and vitamin D levels do not predict low bone density in $\mathrm{AN}[49,59]$.

Certain medications commonly used in AN have effects on bone that may be (i) indirect, and mediated via high prolactin levels and resultant suppressive effects on gonadotropin and gonadal hormone secretion (such as with atypical antipsychotics), or (ii) more direct, as with use of SSRIs. Our studies indicate that a longer duration of SSRI use is predictive of lower bone density in AN, even after controlling for age and duration of illness [70].

\section{Effect of Recovery of Weight and/or Menses on}

\section{Bone Density}

Weight and menses recovery are associated with some increase in bone density in adolescents with AN; however, the rate of bone mass accrual continues to lag behind that seen in healthy adolescents, and 'catch-up' is generally incomplete [57]. Bone turnover markers increase with weight recovery, and early increases in bone formation markers are predictive of subsequent increases in bone mass [59]. It is thus possible that sustained weight recovery will eventually lead to an increase in bone density in adolescent girls with AN. In adults with AN, weight increases are critical for increase in hip bone density, while resumption of menses appears to be critical for increases in lumbar spine bone density [56].

\section{Calcium and Vitamin D Supplements}

Multiple studies have now shown that use of calcium and vitamin D supplements is not effective in increasing bone density in AN $[49,71]$. However, recommendations are to optimize these supplements given that associated vitamin D deficiency can only further exacerbate the impaired state of bone metabolism in $\mathrm{AN}$.

\section{Replacement of Gonadal Steroids}

Despite the significant impact of hypogonadism on bone density in AN, replacement with oral estrogen has not been demonstrated to be effective in increasing bone density in adult women and adolescent girls with AN in a number of studies primarily administering oral contraceptives [71-73]. The role of transdermal estrogen replacement, which unlike oral estrogen will not reduce IGF-1 levels, and the possible role of testosterone replacement in increasing bone density in AN are currently under investigation. Administration of adrenal steroids (dehydroepiandrosterone) was not effective in increasing bone density in AN in one study [48]. The impact of selective estrogen receptor modulators, such as raloxifene, on bone metabolism has not been examined in $\mathrm{AN}$; however, one small uncontrolled study of 5 women with AN indicated that raloxifene may improve persistent depression (resistant to conventional antidepressants) in this condition [74].

\section{Replacement of IGF-1}

Because IGF-1 deficiency and GH resistance are important determinants of low bone density in $\mathrm{AN}$, we have examined the impact of IGF-1 replacement on bone turnover markers and bone density in adolescent girls and women with AN. We found significant increases in mark- 
ers of bone formation following rhIGF-1 administration in women and girls with AN $[58,68,75]$, and an increase in bone density in adult women when rhIGF-1 was given with oral estrogen [68]. Because bone density will continue to decline in women with $\mathrm{AN}$ and persistent low weight, this has been the first intervention shown to prevent further bone loss and cause a gain in bone mass despite low weight compared to placebo.

\section{Bisphosphonates}

One double-blind randomized controlled trial of alendronate versus placebo in adolescents with AN showed no benefit to spine bone density and only minimal increases in femoral neck bone density (after controlling for weight changes) [76]. In contrast, a small study with a shorter (9-month) duration of risedronate administration indicated a $5 \%$ increase in bone density in adult women with AN while on risedronate [77]. Further randomized placebo-controlled trials are needed to determine the utility of bisphosphonates in treating low bone mass in women with AN.

\section{Conclusion}

AN is associated with adaptive changes in many neuroendocrine axes, which then have an impact on bone metabolism and contribute to low bone density. Currently, no approved effective therapy is available that reverses the state of low bone density in this condition. Weight gain to a point where menstrual function is restored and weight is within the normal range for height is to be strongly encouraged, and calcium and vitamin D supplementation should be optimized. Further trials are required to identify therapeutic strategies that will lead to a clinically significant increase in bone density in this condition.

\section{Acknowledgement}

This work was supported in part by NIH grants 1 UL1 RR025758-01, DK 062249 and K23 RR018851.

\section{Disclosure Statement}

The authors have no conflicts of interest to disclose.

\section{References}

1 APA: Diagnostic and Statistical Manual of Mental Disorders, ed 3 Washington, American Psychiatric Association, 1987.

- 2 Lucas AR, Beard CM, O'Fallon WM, Kurland LT: 50-year trends in the incidence of anorexia nervosa in Rochester, Minn.: a population-based study. Am J Psychiatry 1991; 148:917-922.

3 Misra M, Miller K, Bjornson J, Hackman A, Aggarwal A, Chung J, et al: Alterations in growth hormone secretory dynamics in adolescent girls with anorexia nervosa and effects on bone metabolism. J Clin Endocrinol Metab 2003;88:5615-5623.

4 Scacchi M, Pincelli A, Caumo A, Tomasi P, Delitala G, Baldi G, et al: Spontaneous nocturnal growth hormone secretion in anorexia nervosa. J Clin Endocrinol Metab 1997;82: 3225-3229.

5 Stoving R, Veldhuis J, Flyvbjerg A, Vinten J, Hangaard j, Koldkjaer O, et al: Jointly amplified basal and pulsatile growth hormone secretion and increased process irregularity in women with anorexia nervosa: indirect evidence for disruption of feedback regulation within the growth hormone insulin-like growth factor-I axis. J Clin Endocrinol Metab 1999;84:2056-2063.
Counts D, Gwirtsman H, Carlsson L, Lesem M, Cutler G: The effect of anorexia nervosa and refeeding on growth hormone-binding protein, the insulin-like growth factors (IGFs), and the IGF-binding proteins. J Clin Endocrinol Metab 1992;75:762-767.

7 Fazeli PK, Misra M, Goldstein M, Miller KK, Klibanski A: Fibroblast growth factor-21 may mediate growth hormone resistance in anorexia nervosa. J Clin Endocrinol Metab 2010;95:369-374.

8 Coskun T, Bina HA, Schneider MA, Dunbar JD, Hu CC, Chen Y, et al: Fibroblast growth factor-21 corrects obesity in mice. Endocrinology 2008;149:6018-6027.

$\checkmark 9$ Kharitonenkov A, Shiyanova TL, Koester A, Ford AM, Micanovic R, Galbreath EJ, et al: FGF21 as a novel metabolic regulator. J Clin Invest 2005;115:1627-1635.

10 Inagaki T, Lin VY, Goetz R, Mohammadi M, Mangelsdorf DJ, Kliewer SA: Inhibition of growth hormone signaling by the fasting-induced hormone FGF21. Cell Metab 2008;8: 77-83.

11 Misra M, Miller K, Kuo K, Griffin K, Stewart V, Hunter E, et al: Secretory dynamics of ghrelin in adolescent girls with anorexia nervosa and healthy adolescents. Am J Physiol Endocrinol Metab 2005;289:E347-E356.
12 Misra M, Miller KK, Herzog DB, Ramaswamy K, Aggarwal A, Almazan C, et al: Growth hormone and ghrelin responses to an oral glucose load in adolescent girls with anorexia nervosa and controls. J Clin Endocrinol Metab 2004;89:1605-1612.

13 Fazeli P, Lawson E, Prabhakaran R, Miller KK, Donoho D, Clemmons DR, et al: Effects of recombinant human growth hormone in anorexia nervosa: a randomized, placebocontrolled study. J Clin Endocrinol Metab 2010;95:4889-4897.

14 Soyka LA, Misra M, Frenchman A, Miller KK, Grinspoon S, Schoenfeld DA, et al: Abnormal bone mineral accrual in adolescent girls with anorexia nervosa. J Clin Endocrinol Metab 2002;87:4177-4185.

15 Hotta M, Ohwada R, Akamizu T, Shibasaki T, Takano K, Kangawa K: Ghrelin increases hunger and food intake in patients with restricting-type anorexia nervosa: a pilot study. Endocr J 2009;56:1119-1128.

16 Misra M, Aggarwal A, Miller KK, Almazan C, Worley M, Soyka LA, et al: Effects of anorexia nervosa on clinical, hematologic, biochemical, and bone density parameters in community-dwelling adolescent girls. Pediatrics 2004;114:1574-1583. 
-17 Misra M, Katzman DK, Cord J, Manning SJ, $>29$ Otto B, Cuntz U, Fruehauf E, Wawarta R, Mendes N, Herzog DB, et al: Bone metabolism in adolescent boys with anorexia nervosa. J Clin Endocrinol Metab 2008;93: 3029-3036.

- 18 Boyar RM, Katz J, Finkelstein JW, Kapen S, Weiner H, Weitzman ED, et al: Anorexia nervosa. Immaturity of the 24-hour luteinizing hormone secretory pattern. N Engl J Med 1974;291:861-865.

-19 Misra M, Prabhakaran R, Miller KK, Tsai P, Lin A, Lee N, et al: Role of cortisol in menstrual recovery in adolescent girls with anorexia nervosa. Pediatr Res 2006;59:598603.

-20 Arvat E, Maccario M, Di Vito L, Broglio F, Benso A, Gottero C, et al: Endocrine activities of ghrelin, a natural growth hormone secretagogue (GHS), in humans: comparison and interactions with hexarelin, a non-natural peptidyl GHS, and GH-releasing hormone. J Clin Endocrinol Metab 2001;86: 1169-1174.

-21 Nakazato M, Murakami N, Date Y, Kojima M, Matsuo H, Kangawa K, et al: A role for ghrelin in the central regulation of feeding. Nature 2001;409:194-198.

-22 Kojima M, Hosoda H, Date Y, Nakazato M, Matsuo H, Kangawa K: Ghrelin is a growthhormone releasing acylated peptide from stomach. Nature 1999;402:656-660.

-23 Takaya K, Ariyasu H, Kanamoto N, Iwakura $\mathrm{H}$, Yoshimoto A, Harada M, et al: Ghrelin strongly stimulates growth hormone release in humans. J Clin Endocrinol Metab 2000; 85:4908-4911.

24 Kluge M, Schussler P, Uhr M, Yassouridis A, Steiger A: Ghrelin suppresses secretion of luteinizing hormone in humans. J Clin Endocrinol Metab 2007;92:3202-3205.

-25 Vulliemoz NR, Xiao E, Xia-Zhang L, Germond M, Rivier J, Ferin M: Decrease in luteinizing hormone pulse frequency during a five-hour peripheral ghrelin infusion in the ovariectomized rhesus monkey. J Clin Endocrinol Metab 2004;89:5718-5723.

-26 Ariyasu H, Takaya K, Tagami T, Ogawa Y, Hosoda K, Akamizu T, et al: Stomach is a major source of circulating ghrelin, and feeding state determines plasma ghrelin-like immunoreactivity levels in humans. J Clin Endocrinol Metab 2001;86:4753-4758.

-27 Misra M, Miller KK, Stewart V, Hunter E, Kuo K, Herzog DB, et al: Ghrelin and bone metabolism in adolescent girls with anorexia nervosa and healthy adolescents. J Clin Endocrinol Metab 2005;90:5082-5087.

-28 Broglio F, Gianotti L, Destefanis S, Fassino S, Abbate Daga G, Mondelli V, et al: The endocrine response to acute ghrelin administration is blunted in patients with anorexia nervosa, a ghrelin hypersecretory state. Clin Endocrinol (Oxf) 2004;60:592-599. Folwaczny C, Riepl R, et al: Weight gain decreases elevated plasma ghrelin concentrations of patients with anorexia nervosa. Eur J Endocrinol 2001;145:669-673.

30 Batterham RL, Cowley MA, Small CJ, Herzog H, Cohen MA, Dakin CL, et al: Gut hormone PYY(3-36) physiologically inhibits food intake. Nature 2002;418:650-654.

31 Misra M, Miller KK, Tsai P, Gallagher K, Lin A, Lee N, et al: Elevated peptide YY levels in adolescent girls with anorexia nervosa. J Clin Endocrinol Metab 2006;91:1027-1033.

32 Fernandez-Fernandez R, Aguilar E, TenaSempere M, Pinilla L: Effects of polypeptide YY(3-36) upon luteinizing hormone-releasing hormone and gonadotropin secretion in prepubertal rats: in vivo and in vitro studies. Endocrinology 2005;146:1403-1410.

33 Cambuli VM, Musiu MC, Incani M, Paderi M, Serpe R, Marras V, et al: Assessment of adiponectin and leptin as biomarkers of positive metabolic outcomes after lifestyle intervention in overweight and obese children. J Clin Endocrinol Metab 2008;93:3051-3057.

34 Housova J, Anderlova K, Krizova J, Haluzikova D, Kremen J, Kumstyrova T, et al: Serum adiponectin and resistin concentrations in patients with restrictive and binge/purge form of anorexia nervosa and bulimia nervosa. J Clin Endocrinol Metab 2005;90: 1366-1370.

35 Misra M, Miller KK, Cord J, Prabhakaran R, Herzog DB, Goldstein M, et al: Relationships between serum adipokines, insulin levels, and bone density in girls with anorexia nervosa. J Clin Endocrinol Metab 2007;92: 2046-2052.

36 Tagami T, Satoh N, Usui T, Yamada K, Shimatsu A, Kuzuya H: Adiponectin in anorexia nervosa and bulimia nervosa. J Clin Endocrinol Metab 2004;89:1833-1837.

37 Lu M, Tang Q, Olefsky JM, Mellon PL, Webster NJ: Adiponectin activates adenosine monophosphate-activated protein kinase and decreases luteinizing hormone secretion in L 3 T2 gonadotropes. Mol Endocrinol 2008;22:760-771.

38 Ahima RS, Flier JS: Leptin. Annu Rev Physiol 2000;62:413-437.

39 Farooqi IS: Leptin and the onset of puberty: insights from rodent and human genetics. Semin Reprod Med 2002;20:139-144

40 Welt CK, Chan JL, Bullen J, Murphy R, Smith P, DePaoli AM, et al: Recombinant human leptin in women with hypothalamic amenorrhea. N Engl J Med 2004;351:987-997.

41 Grinspoon S, Gulick T, Askari H, Landt M, Lee K, Anderson E, et al: Serum leptin levels in women with anorexia nervosa. J Clin Endocrinol Metab 1996;81:3861-3863.

42 Misra M, Miller KK, Kuo K, Griffin K, Stewart V, Hunter E, et al: Secretory dynamics of leptin in adolescent girls with anorexia nervosa and healthy adolescents. Am J Physiol Endocrinol Metab 2005;289:E373-E381.
43 Miller KK, Grinspoon S, Gleysteen S, Grieco KA, Ciampa J, Breu J, et al: Preservation of neuroendocrine control of reproductive function despite severe undernutrition. J Clin Endocrinol Metab 2004;89:4434-4438.

-44 Biller B, Federoff H, Koenig J, Klibanski A: Abnormal cortisol secretion and responses to corticotropin-releasing hormone in women with hypothalamic amenorrhea. J Clin Endocrinol Metab 1990;70:311-317.

45 Misra M, Miller KK, Almazan C, Ramaswamy K, Lapcharoensap W, Worley M, et al: Alterations in cortisol secretory dynamics in adolescent girls with anorexia nervosa and effects on bone metabolism. J Clin Endocrinol Metab 2004;89:4972-4980.

-46 Grinspoon S, Thomas L, Miller K, Pitts S, Herzog D, Klibanski A: Changes in regional fat redistribution and the effects of estrogen during spontaneous weight gain in women with anorexia nervosa. Am J Clin Nutr 2001; 73:865-869.

47 Padmanabhan V, Keech C, Convey EM: Cortisol inhibits and adrenocorticotropin has no effect on luteinizing hormone-releasing hormone-induced release of luteinizing hormone from bovine pituitary cells in vitro. Endocrinology 1983;112:1782-1787.

48 Gordon CM, Grace E, Emans SJ, Feldman HA, Goodman E, Becker KA, et al: Effects of oral dehydroepiandrosterone on bone density in young women with anorexia nervosa: a randomized trial. J Clin Endocrinol Metab 2002;87:4935-4941.

49 Soyka LA, Grinspoon S, Levitsky LL, Herzog DB, Klibanski A: The effects of anorexia nervosa on bone metabolism in female adolescents. J Clin Endocrinol Metab 1999;84: 4489-4496.

50 Haas V, Onur S, Paul T, Nutzinger DO, BosyWestphal A, Hauer M, et al: Leptin and body weight regulation in patients with anorexia nervosa before and during weight recovery. Am J Clin Nutr 2005;81:889-896.

51 Wren A, Small C, Ward H, Murphy K, Dakin C, Taheri S, et al: The novel hypothalamic peptide ghrelin stimulates food intake and growth hormone secretion. Endocrinology 2000;141:4325-4328.

52 Bachrach LK, Katzman DK, Litt IF, Guido D, Marcus R: Recovery from osteopenia in adolescent girls with anorexia nervosa. J Clin Endocrinol Metab 1991;72:602-606.

53 Grinspoon S, Miller K, Coyle C, Krempin J, Armstrong C, Pitts S, et al: Severity of osteopenia in estrogen-deficient women with anorexia nervosa and hypothalamic amenorrhea. J Clin Endocrinol Metab 1999;84: 2049-2055.

54 Grinspoon S, Thomas E, Pitts S, Gross E, Mickley D, Miller K, et al: Prevalence and predictive factors for regional osteopenia in women with anorexia nervosa. Ann Intern Med 2000;133:790-794. 
55 Bredella MA, Fazeli PK, Miller KK, Misra M, Torriani M, Thomas BJ, et al: Increased bone marrow fat in anorexia nervosa. J Clin Endocrinol Metab 2009;94:2129-2136.

-56 Miller KK, Lee EE, Lawson EA, Misra M, Minihan J, Grinspoon SK, et al: Determinants of skeletal loss and recovery in anorexia nervosa. J Clin Endocrinol Metab 2006;91: 2931-2937.

-57 Misra M, Prabhakaran R, Miller KK, Goldstein MA, Mickley D, Clauss L, et al: Weight gain and restoration of menses as predictors of bone mineral density change in adolescent girls with anorexia nervosa-1. J Clin Endocrinol Metab 2008;93:1231-1237.

-58 Grinspoon S, Baum H, Lee K, Anderson E, Herzog D, Klibanski A: Effects of short-term recombinant human insulin-like growth factor I administration on bone turnover in osteopenic women with anorexia nervosa. J Clin Endocrinol Metab 1996;81:3864-3870.

-59 Soyka L, Misra M, Frenchman A, Miller K, Grinspoon S, Schoenfeld D, et al: Abnormal bone mineral accrual in adolescent girls with anorexia nervosa. J Clin Endocrinol Metab 2002;87:4177-4185.

60 Biller B, Saxe V, Herzog D, Rosenthal D, Holzman S, Klibanski A: Mechanisms of osteoporosis in adult and adolescent women with anorexia nervosa. J Clin Endocrinol Metab 1989;68:548-554.

-61 Bauer JS, Link TM: Advances in osteoporosis imaging. Eur J Radiol 2009;71:440-449.

62 Griffith JF, Genant HK: Bone mass and architecture determination: state of the art. Best Pract Res Clin Endocrinol Metab 2008; 22:737-764.
63 Bredella MA, Misra M, Miller KK, Madisch I, Sarwar A, Cheung A, et al: Distal radius in adolescent girls with anorexia nervosa: trabecular structure analysis with high-resolution flat-panel volume CT. Radiology 2008; 249:938-946.

64 Lawson EA, Miller KK, Bredella MA, Phan C, Misra M, Meenaghan E, et al: Hormone predictors of abnormal bone microarchitecture in women with anorexia nervosa. Bone 2010;46:458-463.

65 Milos G, Spindler A, Ruegsegger P, Seifert B, Muhlebach S, Uebelhart D, et al: Cortical and trabecular bone density and structure in anorexia nervosa. Osteoporos Int 2005; 16 : 783-790.

66 Walsh CJ, Phan CM, Misra M, Bredella MA, Miller KK, Fazeli P, et al: Women with anorexia nervosa: finite element and trabecular structure analysis in anorexia nervosa via flat-panel volume CT. Radiology 2010:257: 167-174.

67 Miller KK, Lawson EA, Mathur V, Wexler TL, Meenaghan E, Misra M, et al: Androgens in women with anorexia nervosa and normal-weight women with hypothalamic amenorrhea. J Clin Endocrinol Metab 2007; 92:1334-1339.

68 Grinspoon S, Thomas L, Miller K, Herzog D, Klibanski A: Effects of recombinant human IGF-I and oral contraceptive administration on bone density in anorexia nervosa. J Clin Endocrinol Metab 2002;87:2883-2891.

69 Utz AL, Lawson EA, Misra M, Mickley D, Gleysteen S, Herzog DB, et al: Peptide YY levels and bone mineral density in women with anorexia nervosa. Bone 2008;43:135139.

70 Misra M, Le Clair M, Mendes N, Miller KK, Lawson EA, Meenaghan E, et al: Use of SSRIs may impact bone density in adolescent and young women with anorexia nervosa. CNS Spectr 2010 (in press).
71 Klibanski A, Biller B, Schoenfeld D, Herzog $D$, Saxe V: The effects of estrogen administration on trabecular bone loss in young women with anorexia nervosa. J Clin Endocrinol Metab 1995;80:898-904.

-72 Strokosch GR, Friedman AJ, Wu SC, Kamin $\mathrm{M}$ : Effects of an oral contraceptive (norgestimate/ethinyl estradiol) on bone mineral density in adolescent females with anorexia nervosa: a double-blind, placebo-controlled study. J Adolesc Health 2006;39:819-827.

73 Golden NH, Lanzkowsky L, Schebendach J, Palestro CJ, Jacobson MS, Shenker IR: The effect of estrogen-progestin treatment on bone mineral density in anorexia nervosa. J Pediatr Adolesc Gynecol 2002;15:135-143.

74 Yokoyama S, Sugiyama N, Sugiyama E, Amano N: Five female cases of prolonged depression in chronic anorexia nervosa treated with selective estrogen receptor modulator raloxifene-augmented therapy. J Clin Psychopharmacol 2008;28:721-722.

75 Misra M, McGrane J, Miller KK, Goldstein MA, Ebrahimi S, Weigel T, et al: Effects of rhIGF-1 administration on surrogate markers of bone turnover in adolescents with anorexia nervosa. Bone 2009;45:493-498.

76 Golden NH, Iglesias EA, Jacobson MS, Carey D, Meyer W, Schebendach J, et al: Alendronate for the treatment of osteopenia in anorexia nervosa: a randomized, double-blind, placebo-controlled trial. J Clin Endocrinol Metab 2005;90:3179-3185.

77 Miller KK, Grieco KA, Mulder J, Grinspoon S, Mickley D, Yehezkel R, et al: Effects of risedronate on bone density in anorexia nervosa. J Clin Endocrinol Metab 2004;89:39033906. 